nine centres is given below, with the names of the participating physicians in parentheses, together with (1) the independent clinical assessors, and (2) the administrative, nursing, and technical staff who took a major part in running the trial during its four years. The breathing exercises were specially devised for the trial by Dr. P. J. D. Heaf and Dr. G. P. Maher-Loughnan in the Chest Department at University College Hospital, London. The illustrations in the booklet containing details of the breathing exercises were drawn by Miss C. Schmolle. The criteria used for classifying the type of asthma were recommended by Dr. J. Pepys, who made the final decision in cases of doubt. The secretarial work was undertaken by Mrs. D. Williams, who also painstakingly transcribed the monthly diary recordings and helped with the analysis of results.

Chest Clinic, Knightswood Hospital, Glasgow (Dr. J. A. Crocket): (1) Dr. C. D. Anderson, Dr. C. Johnston; (2) Sister MacLeod, Staff Nurse Mitchell, Dr. J. F. Boyd, Staff Nurse McRe, Mrs. Corrigan

Ransom Hospital, Mansfield (Dr. D. Davies): (1) Dr. W. H. R. Smith ;

(2) Miss B. Buck.

Worcester Royal Infirmary (Dr. S. Z. Kalinowski): (1) Dr. E. N. Moyes :
(2) Mrs. M. J. Rowlands, Sister A. Hartley, Sister R. James, Mr. G. H.

Green. Simmonds, Dr. H. Bruckner, Dr. H. Lawrence ; (2) Mrs. H. Snowden, Sister B. Wood, Staff Nurse $M$. Ellis

Colindale Hospital, London (Dr. G. P. Maher-Loughnan): (1) Dr. W. E. Snell, Dr. M. K. Sarin; (2) Mrs. M. J. Curry, Mr. B. J. Newman.

University College Hospital, London (Dr. M. K. McAllen): (1) Dr. P. J. D. Heaf ; (2) Miss P. McInroy.

Birmingham Chest Clintic (Dr. J. Morrison Smith): (1) Dr. V. H. Springett, Dr. H. E. Thomas; (2) Mrs. J. Morris, Mrs. Y. Jones.

Luton Chest Clinic (Dr. J. Brian Shaw: (1) Dr. S. G. Maddock, Dr. J. Clifford-Firth, Dr. L. Ghosh ; (2) Dr. H. Banks-Smith, Mrs. C. Teale, Sister Kennedy, Sister E. M. Waldron, Sister D. Givan.

Chest Clinic, St. Helen's Hospital, Ipswich (Dr. C. J. Stewart): (1) Dr. D. Dr. M. Dixon, Dr. A. Lintott.

REFERENCES

Maher-Loughnan, G. P., Macdonald, N., Mason, A. A., and Fry, L. (1962). Brit. med. $\ddot{\text { f., }} 2,371$.

Moore, N. (1965). F. psychosom. Res., 9, 257.

Smith, J. Morrison, and Burns, C. L. C. (1960). Brit. F. Dis. Chest, 54,

\title{
Osteoporosis of Lumbar Vertebrae and Calcification of Abdominal Aorta in Women Living in Durban
}

\author{
C. E. DENT, ${ }^{*}$ M.D., F.R.C.P., F.R.S. ; H. E. ENGELBRECHT, † M.B., D.M.R.D. ; R. C. GODFREY, ¥ M.B., M.R.C.P.
}

\author{
[With Special Plate facing Page 94]
}

Brit. med. F., 1968, 4, 76-79

ummary : To try to establish whether mechanical stress
and muscular activity in earlier life influence the
incidence and severity of spinal osteoporosis in old age
lateral x-ray films of the lumbar vertebrae were obtained
from three matched groups, each of 100 women 50 to 90
years old. Group A was of rural Bantu accustomed to
carrying heavy loads on their heads. Group B was of
urban Bantu, mainly in domestic service. Group C was
of women of European origin.

Severe osteoporosis occurred in three cases from group A, two from group B, and 14 from group C. Lesser degrees of osteoporosis could not be assessed precisely enough for inclusion in these figures. Evenly biconcave vertebral bodies, strongly suggestive of osteomalacia, were seen in $\mathbf{1 0}$ from group $A$, five from group $B$, and one from group C. In many Bantu subjects the fifth lumbar vertebra appeared flattened though of good radiodensity and with no marked changes in the other vertebrae. Twenty-eight of these were from group A, 16 from group $B$, and none from group $C$.

About a third of each group showed severe degenerative changes in the spine; another third showed milder changes. More cases of spondylolisthesis occurred in the Bantu groups than in the white group. Severe calcification in the abdominal aorta was noted in 24 women in group C. Mild signs occurred in 35 further women from group $C$, in six from group $B$, and in only one from group $A$.

\section{Introduction}

Osteoporosis is seen most commonly in old age, and by some it is regarded as an integral part of the normal ageing process (reviewed by Rose, 1967). Other factors, especially hormonal, are known to play a significant part in the development of

* Professor of Human Metabolism, University College Hospital Medical School, London W.C.1.

t X-ray Department, King Edward VIII Hospital, Durban.

$¥$ Department of Medicine, King Edward VIII Hospital, Durban. Now at National Hospital for Nervous Diseases, London. osteoporosis. However, prolonged immobilization, as after paralysis or after fracture, can also produce severe osteoporosis of the affected part. No cl:ar evidence exists about the part that might be played by lesser degrees of immobilization or of minor changes of activity over very long periods, nor is it clear how far the reverse may be true-namely, the possibly beneficial effect of great activity on new bone formation.

In the work described here an attempt has been made to establish whether the incidence and severity of osteoporosis of the spine appearing in old age is influenced in any way by mechanical stress and muscular activity during earlier life. To do this we chose to examine the lumbar vertebrae of matched groups of women, 50 to 90 years old, from two different races in Durban, South Africa, where there are excellent medical facilities for this purpose. Many differences exist between the ways of life of Bantu and of white women in and around Durban, but one of the most striking concerns the amount of mechanical stress to which their spines are subjected during childhood, young adulthood, and middle age. It is the practice of rural Bantu women to carry loads of all kinds on their heads. Such loads, usually of firewood or buckets full of water, may approach $2 \mathrm{cwt}$. (100 kg.) and they are often carried for distances of several miles. They begin to carry loads in this way from about 8 years of age, so the effect, if any, of weight-bearing covers an important period of skeletal maturation and growth. As the study proceeded we also decided to record some other features shown on the $x$-ray films.

Nordin (1966) studied the incidence of osteoporosis in about 1,000 normal male and female adults of various ages in 10 different countries. That study was intended particularly to note the effects of diet and of age. We are unaware of any study which is concerned only with the possible effect of exercise and which has used a more narrowly demarcated human population.

\section{Case Material}

The groups were made up as follows:

Group $A: 100$ Bantu women who had spent their entire lives in rural areas working on the farms and who often carried heavy loads on their heads. 
Group $B: 100$ Bantu women who had migrated from the country to Durban, and had worked as domestic servants for the major part of their lives.

Group $C: 100$ white women of European descent who had resided for most of their lives in the city of Durban.

Unfortunately the distinction between groups $A$ and $B$ was not as sharp as was hoped, mainly because most domestic servants were unable to give the exact age at which they had migrated to an urban environment. Even after moving many had continued to carry heavy loads-for example, dustbinson their heads, and preferred to use this method also for smaller loads such as cans of beer.

\section{Method of Selection of Patients}

Bantu Patients.-Between November 1966 and March 1967 the female wards of King Edward VIII Hospital were visited regularly. Suitable cases for the survey were pointed out by the sisters. The interpreter was a medical social worker well versed in Zulu history and custom. Hospital notes were inspected, and if the diagnosis was suitable a patient was asked whether she would be willing to take part. The following questions were asked through the interpreter:

(1) Age of patient: This was never memorized as such, but was discovered mainly by means of a historical questionary which comprised about 50 items oovering the years 1880-1910; the interpreter felt that she was able to be accurate to within two years. Particularly useful events proved to be the rhinderpest plague of 1897, the Anglo-Boer War (1899-1902), and the snow blizzard of 1905.

(2) Previous work of patient-that is, farm worker or domestic servant, and whether much heavy carrying.

(3) A rough history of the dietary habit. It was found that this consisted either of a predominantly cereal diet with very little meat or milk or, in the case of the domestic workers, a good mixed diet.

(4) Whether or not there was a positive history of back pain.

White Patients.-These patients were all living in Durban, and were having a normal European diet. The same history was taken from them. Nearly all were of British origin, and their admissions were for various causes unconnected with skeletal disease.

The patient was measured (crown-pubis, pubis-heel, and span) and sent for $x$-ray examination. Patients were excluded if they had been immobilized for more than a week, or were suffering from systemic disease or receiving drugs known to affect bone metabolism. Most of the Bantu patients in fact were suffering from pneumonia or acute amoebic dysentery.

The survey was continued until 100 suitable patients had been found for each group. To boost the numbers of patients in group B, an old people's home was visited and 30 suitable
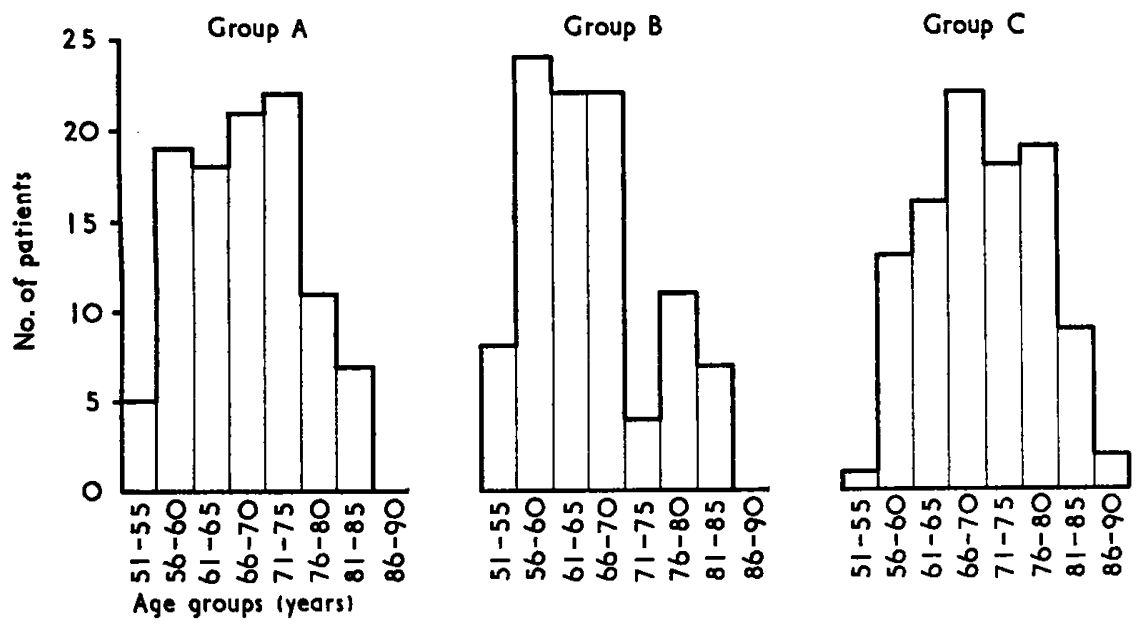

Age distribution of the three groups. subjects were found. The $x$-ray films were then sorted out into their three respective groups.

Age (Mean) of the Three Groups.-The age distribution of the three groups is shown in the Chart. The average age was 68.5 years for group A, 66.3 years for group B, and 70.4 years for group $C$.

\section{X-ray Films}

One lateral view of the lumbar spine only was taken for each patient. Specialized techniques were not used to standardize the bone density. Conventional radiographic equipment and technique were employed with standard kilovoltage, milliamperage, and exposure-time variation according to the thickness of the patient.

The complete series of 300 films was examined both in South Africa and in London. For the London assessment the films were arranged in random order and the observations made without knowledge of the group from which each film was taken. It was found that there were six features which merited special attention.

\section{Osteoporosis}

In the present series, where no attempt was made to standardize the technical aspects of the $x$-ray films other than to ensure a good film suitably centred, we decided to rely on a purely visual assessment of the vertebral shape and structure with no attempt to assess radiodensity of the bones. The radiological features of established osteoporosis of the spine were well known (Cooke, 1955 ; Jesserer, 1963 ; Rose, 1964 ; Dent and Watson, 1966).

In less-advanced cases, before shape changes in the vertebral bodies have occurred, it is hard to assess the degree of osteoporosis, and even complex methods which aim to quantitate the bone density (Schraer, 1958 ; Nordin et al., 1962) are not

Numbers of Patients with Pathological Changes Seen on Lateral Lumbar X-ray

\begin{tabular}{|c|c|c|c|}
\hline$X$-ray Signs of & $\begin{array}{c}\text { Group A } \\
\text { (Rural } \\
\text { Bantu) }\end{array}$ & $\underset{\substack{\text { Group B } \\
\text { Bantu) }}}{\text { Urbanized }}$ & $\begin{array}{l}\text { Group C } \\
\text { (Whites) }\end{array}$ \\
\hline 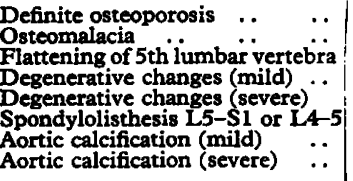 & $\begin{array}{r}3 \\
10 \\
28 \\
31 \\
26 \\
8 \\
1 \\
0\end{array}$ & $\begin{array}{r}2 \\
5 \\
16 \\
31 \\
38 \\
8 \\
6 \\
0\end{array}$ & $\begin{array}{r}14 \\
1 \\
0 \\
27 \\
31 \\
4 \\
35 \\
24\end{array}$ \\
\hline
\end{tabular}

wholly satisfactory (Dent and Watson, 1966). There were many films in which the presence of osteoporosis could be suspected by an apparent rarefaction of the bones but in which there were no more specific changes such as Schmorl's nodes and wedging of the vertebral bodies. We finally decided to group the films into three categories only: (1) normal, (2) ambiguous, and (3) definite vertebral body changes due to osteoporosis. Fig. 1 (Special Plate) gives an example of a definitely osteoporotic spine from the series.

Our results are shown in the Table. It will be noted that there is an increased incidence of definite osteoporosis among the white patients. There was no clear difference between rural Bantu and urbanized Bantu. The mean age of the three osteoporotic patients in group A was 76.6 years, of the two in group B 65.5 years, and of the 14 in group $C 75.4$ years.

Eleven of the 14 osteoporotic patients from group $C$ had a pubis-heel measure- 
ment more than $5 \mathrm{~cm}$. greater than the crown-pubis measurement. All the osteoporotic Bantu patients had much more than this degree of shortening, but little significance can be attached to measurements in African Negroes, whose limbs are always relatively longer than those of Caucasians. For example, in this series of cases the average difference between the crownpubis and pubis-heel measurement was $6.65 \mathrm{~cm}$. in the Bantu, and only $3.68 \mathrm{~cm}$. in the Whites (excluding those cases with definite osteoporosis).

\section{Osteomalacia}

A number of films in this series showed an even biconcavity of the vertebral bodies typical of osteomalacia. Fig. 2 (Special Plate) shows a gross example of this change, and the Table gives the number of such films found in this series. Though the figures are not large, it is of interest that only one case occurred in the well-nourished white patients and 10 cases in the rural Bantu. The diet of the rural Bantu consists mainly of cereals with very little meat or milk, and the vitamin D content of this diet is low. However, there was always plenty of sunshine to help synthesize the vitamin on the exposed skin.

\section{Flattening of Fifth Lumbar Vertebra}

In 44 of the 200 Bantu women (28 of the rural and 16 of the urbanized), there was a characteristic change in the shape of the fifth lumbar vertebra (Special Plate, Fig. 3). It will be noted that the bone density is good but that there is a flattening and increase in the anteroposterior diameter. In some cases there was also anterior wedging. Along with this it was noted that the disc space was well preserved and even perhaps widened. A further common finding was a marked loss of the normal lumbar curve. One of us (H. E. E.) has a wide experience of Bantu spines, and has noted that these changes are very common among patients beyond middle age. Whether these changes are related to the high stresses to which their spines are exposed during earlier life (Jonck, 1964) remains an open question, but we do note that there was more of the flattening in group A than in group B. We had to be careful not to assess this as one of the changes in shape due to osteoporosis.

\section{Degenerative Changes}

Osteophyte formation, disc narrowing, and disc calcification were used as guides to the degree of degenerative disease present in this series of films. There was very little difference in the incidence of such changes in the three groups. The degree of severity was closely related to increasing age.

\section{Spondylolisthesis}

Both of the Bantu groups contained more cases of spondylolisthesis than the white group. The increased incidence may be due only to the greater amount of trauma to which the Bantu spine is subjected. However, it is well established that the pelvis of the Bantu women is tilted forward in comparison with white women, and the greater anterior lumbosacral angle may have some bearing on the tendency to spondylolisthesis.

\section{Aortic Calcification}

Here we found the most significant differences between the groups. All the severe aortic calcification (Special Plate, Fig. 4) and most of the lesser degrees of this were found among the white patients of group C. There was no tendency for the severe calcification to occur in the more osteoporotic spines.

\section{Discussion}

The original project was aimed to be a pilot survey to determine the long-term and possibly beneficial effects of heavy weight-bearing on the bones of the spine. It was supposed that, as can occur with long bones, the stresses and strains of weight-bearing might lead to the formation in early adult life of a much stronger spine than usual. If so, this should protect the spine in later life from the development of "senile" osteoporosis, since many authors now (references quote by Dent and Watson, 1966) believe that osteoporosis is a slow inevitable process of thinning of the skeleton beginning around 30 years of age, but of very variable rate from person to person, and not usually manifesting symptoms and signs until after 60 years of age. At this latter stage it is easy to apply the name " senile" or even, if in a woman, "postmenopausal," to the osteoporosis then present.

We were anxious to test this theory by comparing the $x$-ray films of the spines of women who had regularly carried heavy weights on their heads with those of suitable control groups of less active subjects. We were in some trouble here, as it was not possible to be certain, say, that a given woman of 70 years of age had or had not been carrying heavy weights on her head till the age of 30 years, as the memory of such women was sometimes imperfect. We decided to choose a group of urban Africans of comparable age to compare with the similar group of rural Africans. The rural people were certainly very active in the sense we wanted, but it is likely that many of the urban people were also pretty active, and certainly they too were accustomed to carrying less heavy loads on their heads. Also some might have migrated from the countryside more recently than we were told. A group of white women of similar age distribution was also collected for comparison. The whole survey was limited to women, as they suffer so much more from osteoporosis than do men, and, further, if lack of exercise was an important contributory reason for this rather than the usual much maligned menopause, this effect should show better in women, since they tend to vegetate more than men in old age. Furthermore, the situation in Bantu men is complicated by the common occurrence of severe osteoporosis associated with haemosiderosis (Seftel et al., 1966).

Our results show that the two groups of African women were almost the same with regard to the degree of osteoporosis. There was a much lower incidence in both these groups than in the group of white women. This is an important finding, not quite in the way we had originally expected, and it needs detailed study in a further survey directed differently from this one, for the social and dietary habits of the Africans and Whites are so different that at this stage it is not possible to say what the difference found in their spines is due to.

Quite incidental to the original project was our finding of very marked differences in the amount of calcification seen in the abdominal aorta on the $x$-ray films of the lateral lumbar vertebrae. This should not have surprised us, as there is a considerable literature on the apparent immunity of unwesternized Africans to degenerative arterial disease (discussed by Davidson and Passmore, 1959). However, the size of the difference did surprise us, also the possibility that the small number of calcified aortae found in the urban Africans might represent a real difference with the rural African group, who showed only one case of mild aortic calcification. There was no positive correlation between the patients with aortic calcification and those with severe osteoporosis, as was observed by Bernstein et al. (1966), who took similar $x$-ray views in their survey of the inhabitants of Dakota in high and low fluoride areas.

The assessment of the degree of osteoporosis was done blindly by one of us after assessment had been carried out with knowledge of the diagnosis by the other two. There was good agreement. We had intended to repeat the process to see how we agreed among ourselves on a further fully blind assessment. 
This was not possible, however, for we soon realized we could distinguish the $x$-ray films of most of the whites from those of the Africans by the different incidence of aortic calcification and the rather characteristic shape of the lower lumbar vertebrae of many of the Africans.

We wish to thank the Medical Research Council for their support and for a grant to one of us (R. C. G.). Thanks are due to many members of the staff of King Edward VIII Hospital, Durban, for making this project possible. Professor E. B. Adams put many facilities at our disposal, including the medical social worker, Miss Ngwane, to whom we are especially grateful. The high quality of the $x$-ray films was entirely due to Professor B. Sachs and the $x$-ray department of the Addington and King Edward VII Hospitals, Durban. The extra work we imposed on them was borne in the normal course of their workings. We thank the consultants of these hospitals for letting us use cases under their care, and also Miss Y. Brown, director of the Lamontville Old People's Home, Durban.

\section{REFERENCES}

Bernstein, D. S., Sadowsky, N. Hegsted, D. M., Guri, C. D., and Stare, F. J (1966) 7 Amer med Ass, 198,499

Nordin, B. E. C. (1966). Clin. Orthop. No. 45, p. 17.

Cordin, B. E. C. (1966), Clin. Ortho

Cooke, A. M. (1955). Lancet, 1, 929. Human Nutrition and Dietetics, 3rd ed., p. 400, Edinburgh.

Dent, C. E., and Watson, L. (1966). Postgrad. med. F., October Suppl. Jesserer, H.' (1963). In Ostéoporose, edited by $\mathrm{E}$. Blaschker, Berlin.

Jonck, L. M. (1964). S. Afr. F. Radiol., 2, 25.

Nordin, B. E. C., Barnett, E., MacGregor, J., and Nisbet, J. (1962). Brit. med. 7., 1, 1793.

Rose, G. A. (1964). Clin. Radiol., 15, 75.

Rose, G. A. (1967). Sci. Basis Med., p. 252

Schraer, H. (1958). 尹. Pediat., 52, 416 .

Seftel, H. C., et al. (1966). Brit. med. F., 1, 642.

\title{
Prognosis in Tetraplegia
}

\author{
J. R. SILVER, M.B., B.S., M.R.C.P.ED. ; N. O. K. GIBBON, M.CH., F.R.C.S.
}

Cummary : A total of 141 cases of traumatic tetraplegia were admitted to the Liverpool Paraplegic Centre between 1947 and 1967. Most of the deaths occurred within three months of injury, and comparison with other centres suggests that the early mortality could be reduced by more use of mechanical respirators.

Urological complaints and pressure sores are hazards that can be overcome by careful attention to nursing procedures. Later deaths are more common among patients transferred from the unit to hostels or hospitals than among patients transferred home. Specialist units for these patients improve the quality of their lives as well as their expectation of life. Electronic equipment can also play a large part in helping tetraplegics to play a part in community life.

\section{Introduction}

A total of 626 patients were admitted to the Liverpool Regional Paraplegic Centre between its opening in January 1947 and May 1967. Among these were 196 tetraplegics (179 males and 17 females), their ages ranging from 11 to 75 years. The small number of female patients in this series is partly because there has been a four-bedded female ward only since 1961, but it is also because women are less liable to traumatic tetraplegia, as they do not indulge to the same extent as men in the dangerous activities of motor-cycling and outdoor construction work, nor temperamentally are they so prone to reckless driving and diving.

The total numbers of tetraplegics admitted to the centre compared with the total admissions year by year are set out in Fig. 1, which shows that there has been a progressive increase in the total number of patients admitted. Previous to 1953 very few tetraplegics were admitted, but since 1954 the proportion has averaged about $33 \%$ of the total admissions, without any obvious trend in either direction. In common with other centres (Walsh, 1967), tetraplegics absorb a relatively high proportion of the resources of the centre, and we have therefore turned our attention recently to the special problems affecting patients with cervical involvement.
The cause of the tetraplegia was trauma in 141 cases and multiple sclerosis in 45 . There were 10 miscellaneous medical conditions, such as angioma of the cord, extradural abscess, and transverse myelitis. The prognosis and management of

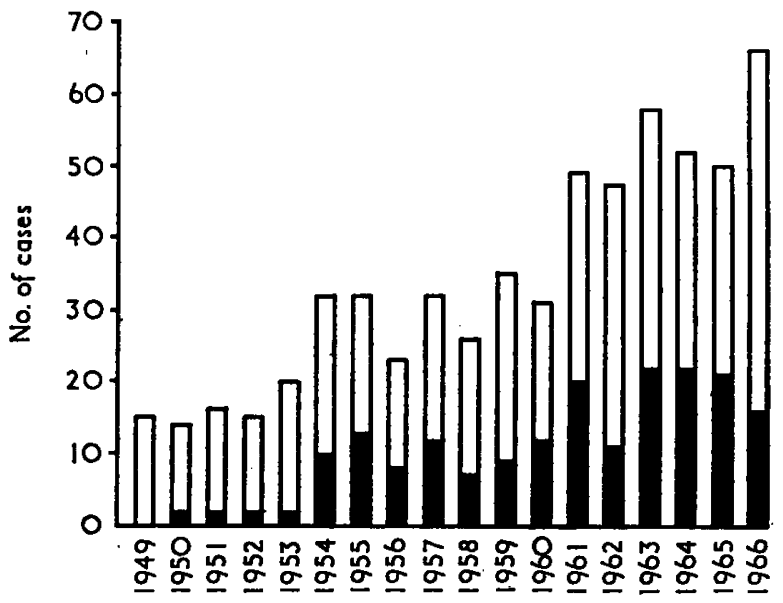

FIG. 1.-Total tetraplegics admitted year by year compared with total admissions. Yearly average is $30 \%$.

multiple sclerosis are dealt with elsewhere (MacAlpine et al., 1955, 1965); this paper is devoted to a consideration of the prognosis in the 141 cases of traumatic tetraplegia.

Breithaupt et al. (1961) have shown that the prognosis differs between complete and incomplete tetraplegia, and so we have taken this into account in presenting our statistics (Table I).

The majority of the patients had been seen for routine follow-up investigations, intravenous pyelography, residual urine check, blood urea, etc., during the last year, and in those who had not (49 patients) a personal follow-up letter was dispatched both to the patient's general practitioner and to the patient. Further information was received on 44 patients, a most gratifying response, so that up-to-date information was available on 135 patients, only six patients being lost to follow-up. 


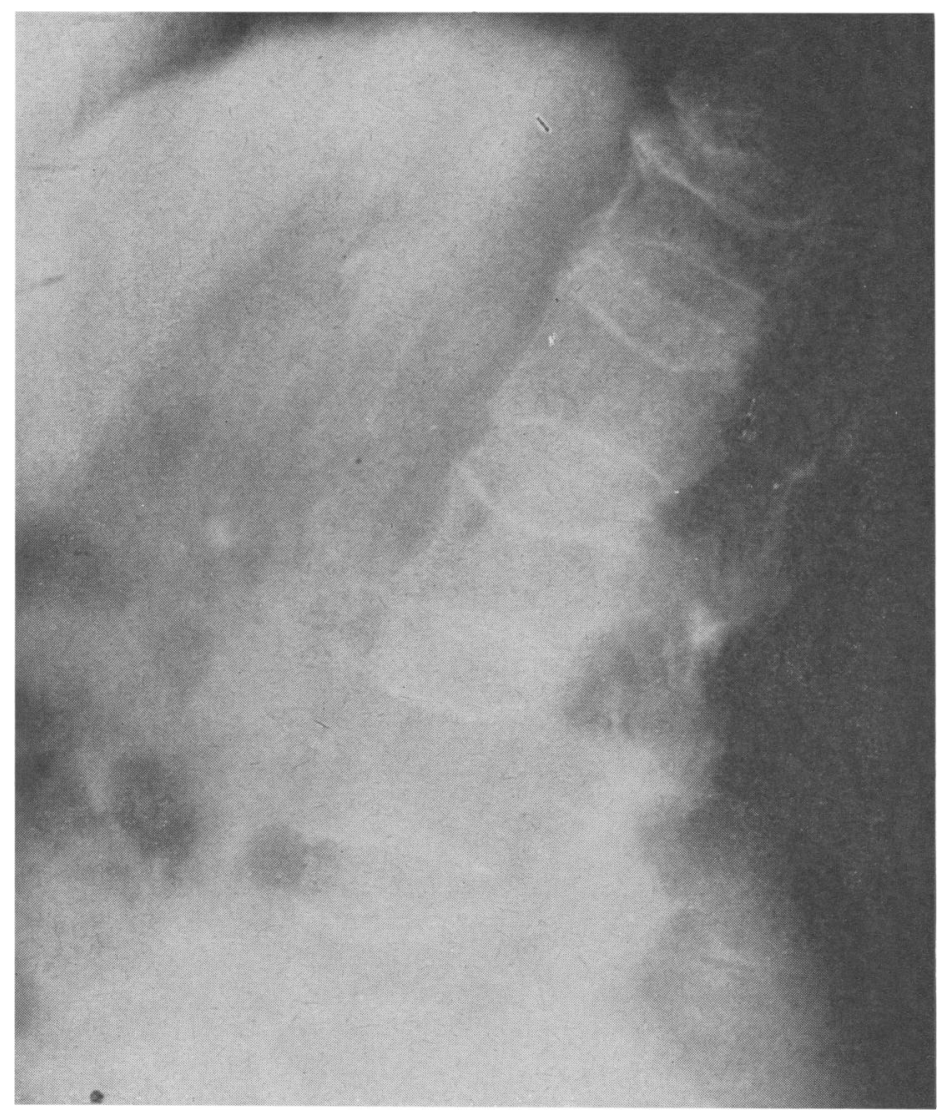

FIG. 1.-An example of osteoporosis with definite structural changes of the vertebral bodies. Note the unevenness of the compression fractures.

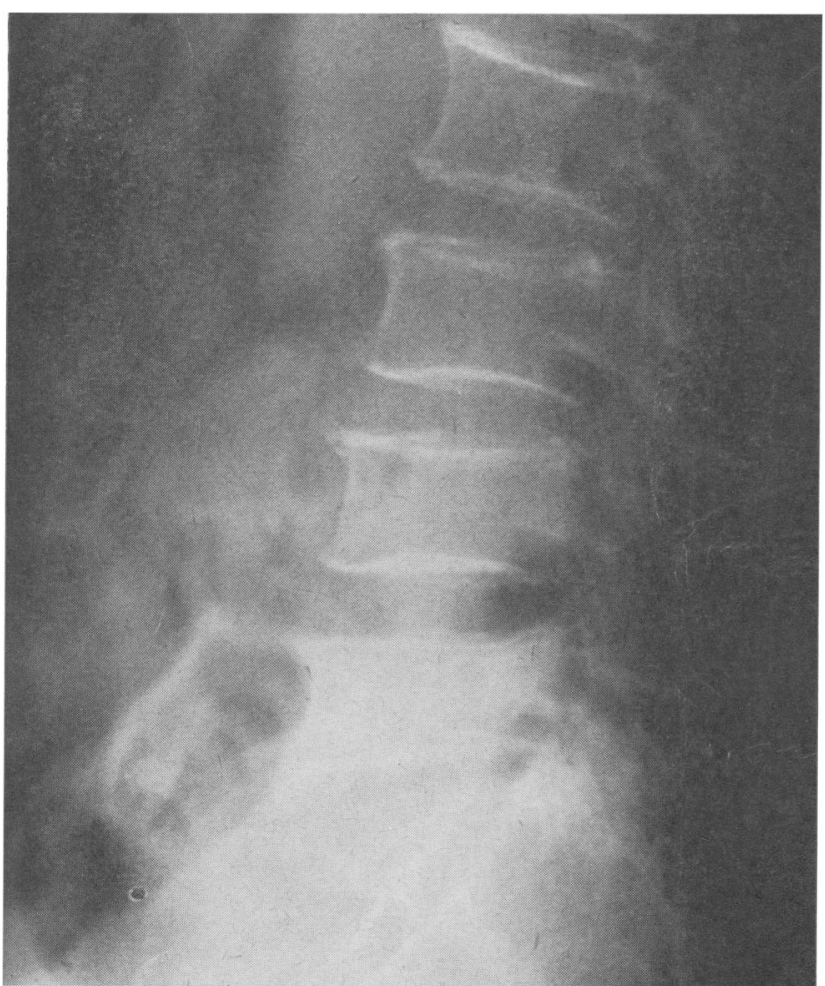

FIG. 3.-Anteroposterior increase in diameter of the fifth lumbar vertebra with preservation of good radiodensity, a frequent finding in group A. Note the wide disc spaces.
A.

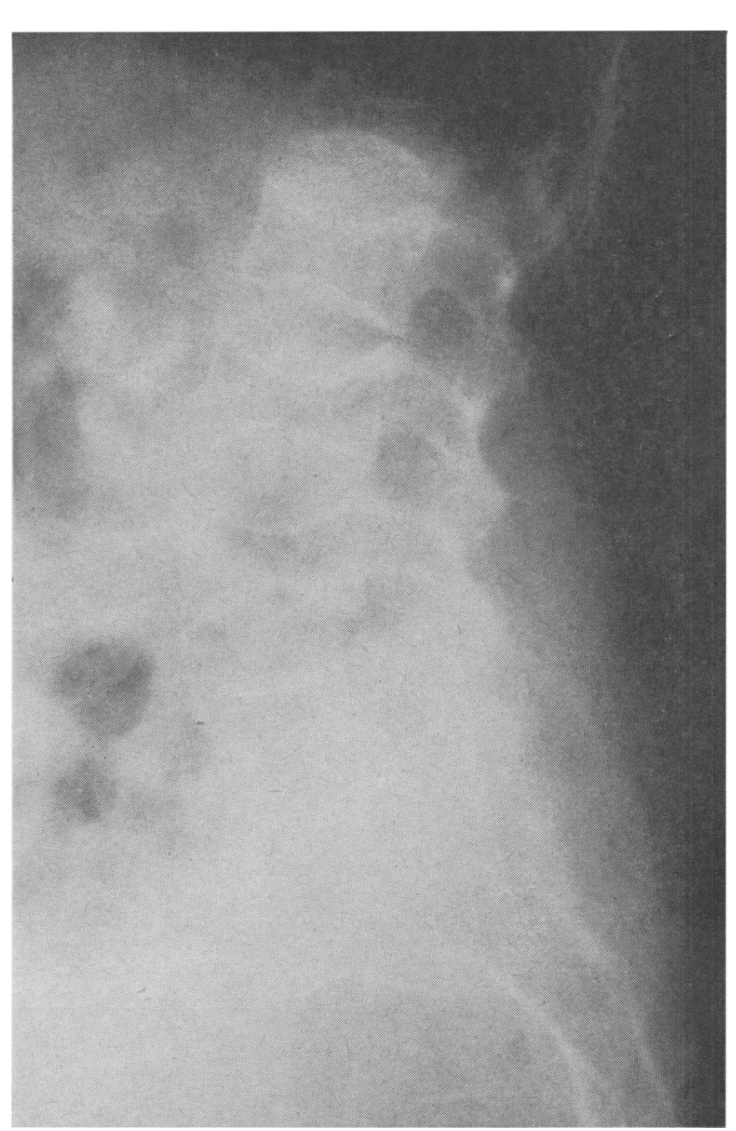

FIG. 2.-An osteomalacic spine. There is even bioconcavity of all the vertebral bodies.



FIG. 4.-An example of aortic calcification from group $C$. 